\title{
ASSIGNMENT OF THE GENE ENCODING TYPE $1 \gamma$ PROTEIN PHOSPHATASE CATALYTIC SUBUNIT (PPPICC) ON HUMAN, RAT, AND MOUSE CHROMOSOMES
}

\author{
Mostafa SaAdat, ${ }^{1}$ Ken Nomoto, ${ }^{1}$ Yusuke Mizuno, ${ }^{1}$ Kunimi Kikuchi, ${ }^{1}$ \\ and Michihiro C. YosHIDA ${ }^{2,3, *}$ \\ ${ }^{1}$ Section of Biochemistry, Institute of Immunological Science, \\ ${ }^{2}$ Chromosome Research Unit, Faculty of Science, and \\ ${ }^{3}$ Laboratory of Cytogenetics, Division of Biological Sciences, \\ Graduate School of Environment Earth Science, \\ Hokkaido University, Sapporo 060, Japan
}

\begin{abstract}
Summary Using fluorescent in situ hybridization (FISH) method, a gene encoding the catalytic subunit of protein phosphatase type $1 \gamma$ (PPP1CC) was mapped to human $12 \mathrm{q} 24.1-\mathrm{q} 24.2$, rat $7 \mathrm{q} 22$, and mouse 10C. These results indicate that the $P P P I C C$ is a member of conserved synteny group between rat chromosome 7, mouse chromosome 10 and human chromosome 12. These data and mapping data about other members of PP1 family show that in spite of the high identity of PP1 isoforms, each isoform is encoded by different genes which located on different chromosomes in human, rat, and mouse.
\end{abstract}

Key Words protein phosphatase type 1, PP1 $\gamma$, comparative gene mapping, FISH

\section{INTRODUCTION}

Various cellular functions are regulated phosphorylation-dephosphorylation of proteins. The physiological importance of protein phosphatase (PP), which functionally counteracts protein kinase, on cellular events has been extensive studied and many important aspects of this enzyme related to cell growth have been revealed (Cohen, 1989). At present, four major classes of PPs (PP1, PP2A, PP2B, and PP2C) have been identified (Cohen, 1989). In the past several years, by using cDNA cloning, there has been increasing knowledge about type 1 protein phosphatases (PP1). These findings demonstrate that the PP1 is a very highly conservative gene family with at least three different genes. PP1 $\gamma$ is one of them

Received July 28, 1995; Revised version accepted December 1, 1995.

* To whom correspondence should be addressed. 
that have been cloned in human (Barker et al., 1993), rat (Sasaki et al., 1990), and mouse (Ohkura et al., 1989; mouse PP1 $\gamma 2$ is designated as dis $2 \mathrm{~m} 1$ ) which showed a high degree of homology with each other. Comparative study of nucleotide and deduced amino acid sequences of PP1 $\gamma 1$ and PP1 $\gamma 2$ suggest that they are derived from the same gene and produced by alternative splicing (Sasaki et al., 1990; Barker et al., 1993). Here, we report the comparative mapping of the gene encoding the catalytic subunit of PP1 $\gamma(P P P I C C)$ to the human, rat, and mouse chromosomes which will provide evolutionary genomic organization in these species.

\section{MATERIALS AND METHODS}

The probe used for mapping was the ApaI-HidIII fragment (about $800 \mathrm{bp}$ ) of noncoding region of the rat PPl $\gamma 1 \mathrm{cDNA}$ (Sasaki et al., 1990). This fragment has no homology with other members of PPl family but shows high level of conservation between human and rat, therefore, we used this cDNA fragment as a probe for gene assignment in human, rat, and mouse chromosomes. The rat cDNA probe detected cross-hybridization signals on human and mouse chromosomes which was critically dependent on the stringency condition, as described previously (Saadat et al., 1995). Each chromosome preparation was made from a male human blood culture, primary cultures of fibroblasts of a male LEC rat and a DRC mouse. Fluorescent in situ hybridization (FISH) was performed using biotinylated cDNA fragment as previously described (Saadat et al., 1995). The precise signal position was determined by the delineation of Q-banding patterns. We have applied the chromosome terminology for ISCN (1978); i.e. human, rat, and mouse

chromosomes by HSA, RNO, and MMU, respectively.

Genomic DNAs were prepared from WKAH rat, C3H mouse, and the rat $\mathrm{X}$ mouse hybrid cell lines ( $\mathrm{Li}$ et al., 1989). Sense and antisense primers were; 5'-CCTCCCACTGCACACTTAAC-3' (nucleotide positions 1,623 to 1,642 of the rat PP1 $\gamma 1$ cDNA clone) and 5'-CTGTGCCAGCAGCCTTGGTG-3' (nucleotide positions 1,743 to 1,762 of the rat PP $1 \gamma 1$ cDNA clone), respectively. PCR was performed using the genomic DNA samples ( $200 \mathrm{ng} /$ reaction), $25 \mathrm{pmol}$ of each primer, 3 unit AmpliTaq polymerase, in $50 \mathrm{ml}$ of reaction mixture. PCR reactions were carried out as follows, $94^{\circ} \mathrm{C}$ for $3 \mathrm{~min}, 65^{\circ} \mathrm{C}$ for $30 \mathrm{sec}, 72^{\circ} \mathrm{C}$ for $30 \mathrm{sec}, 94^{\circ} \mathrm{C}$ for $1 \mathrm{~min}$, for 35 cycles followed by $72^{\circ} \mathrm{C}$ for $10 \mathrm{~min}$. The PCR products were subjected to $4 \%$ agarose gel electrophoresis and visualized with ethidium bromide.

\section{RESULTS AND DISCUSSION}

As shown in Fig. $1 \mathrm{a}-\mathrm{c}$, the human PPPICC was mapped to chromosome 12 at bands q24.1-q24.2. Analysis of 50 human metaphases showed that 4 metaphases had twin-spots on both homologs and 26 metaphases had a double-spot signal on sister chromatids at $\mathrm{q} 24.1-\mathrm{q} 24.2$ of HSA12, showing that the PPPICC located on 

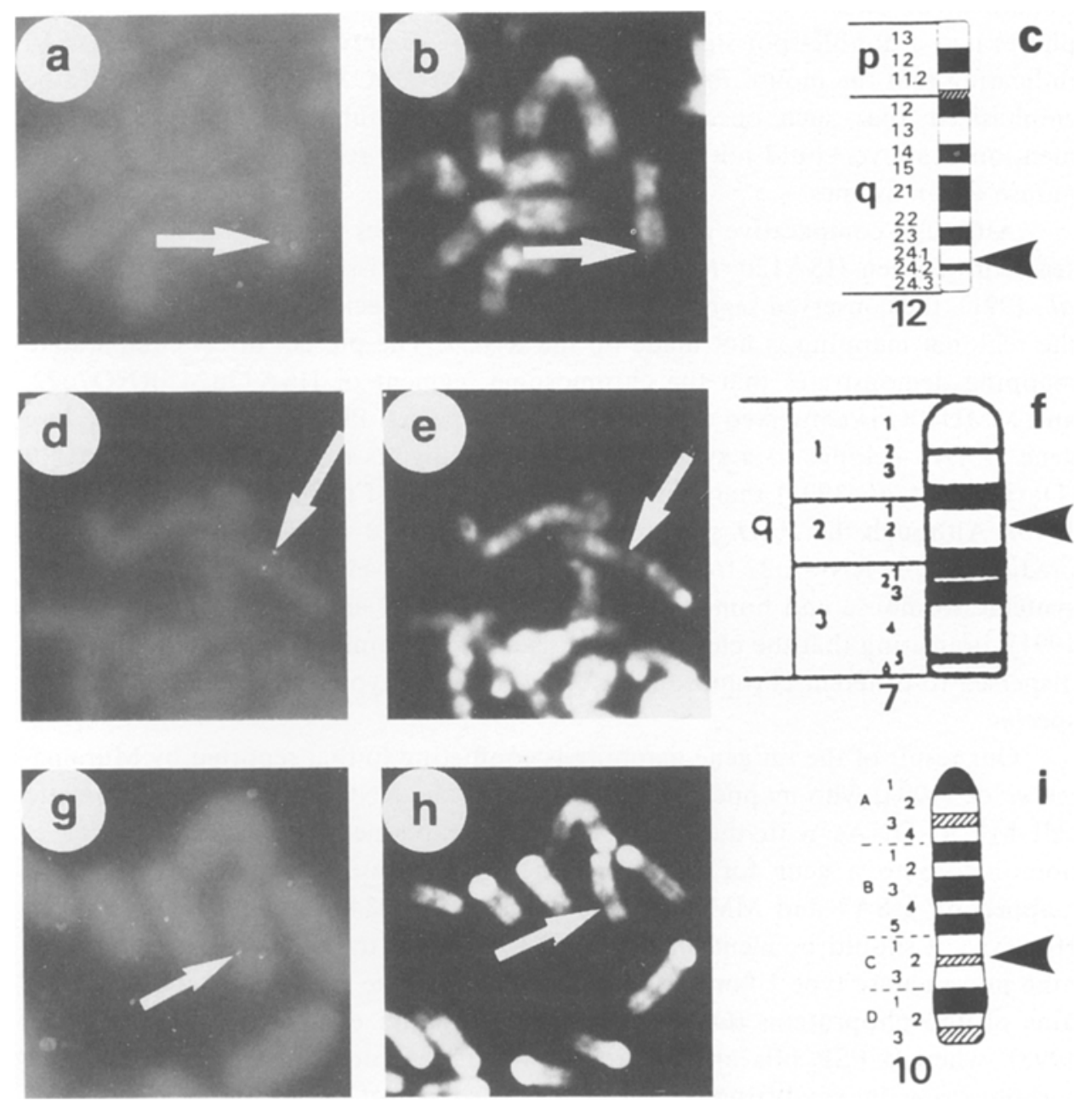

Fig. 1. Chromosomal localization of the human (a-c), rat (d-f), and mouse (g-i) protein phosphatase type $1 \gamma$ gene $(P P P I C C)$ by FISH. The chromosomes were stained with propidium iodide $(\mathrm{a}, \mathrm{d}, \mathrm{g})$ and $\mathrm{Q}$-banded $(\mathrm{b}, \mathrm{e}, \mathrm{h})$. Arrows indicate the positions of hybridization signals. Arrowheads on each ideogram (c, f, i) showed the respective mapped site.

this region. These data confirm the previous assignment (Barker et al, 1993).

For rat mapping, 60 rat metaphases were examined after FISH. Five metaphases had twin-spots on both homologous pairs and 34 metaphases had a twin-spot on one homolog of chromosome 7 at region q22, showing that the Ppp1cc located on RNO7q22 (Fig. $1 \mathrm{~d}-\mathrm{f}$ ).

For mouse chromosome assignment, a total of 50 mouse metaphases was 
examined. Of these 4 cells exhibited twin-spots on both homologs and 22 metaphases had a double-spot signal on one homolog of chromosome 10 at region $C$, indicating that the mouse PppIcc located on MMU10C (Fig. I g-i). It should be emphasized that such specific accumulation of double spot signals, which mentioned above, could not be detected on any other regions of human, rat, and mouse chromosomes.

Although comparative gene mapping demonstrates that there is a conserved segment between HSA12q, MMU10, and RNO7 (Davisson et al., 1991; Levan et al., 1991), the conserved segment among these three species is not defined, because the regional mapping is not made on the RNO7. The present direct comparative mapping demonstrates that the chromosome segment of HSA12q24, RNO7q22, and MMU10C is conserved among these three species. Phenylalanine hydroxylase gene $(P A H)$ belongs to a syntenic group homologolis to HSA12q and MMU10 (Davisson et al., 1991) that was mapped on RNO7 (Fulchignoni-Lataud et al., 1990). Although the $P A H$ was not regionally mapped on RNO7, its location is predicted to be RNO7q22 from the present study. However, other genes on RNO7. syntenic to mouse and human share MMU15, HSA8, and HSA22 (Levan et al., 1991), indicating that the chromosomal segment contained homologous genes has dispersed to different chromosomes during the karyotypic evolution among these species.

Our result of the rat gene mapping is conflicting to that reported by Muramatsu et al. (1994) who mapped the rat Ppplcc on the RNO12 by analyzing somatic cell hybrid DNAs with the PCR. They also explained that the rat Ppplcc is homologous to a gene for phosphoserine phosphatase (PSP) which has been mapped on HSA7 and MMU5 (Lalley and Diaz, 1984; Danesino et al., 1987). However, it should be mentioned that PPl $\gamma$ belongs to the protein serine/threonine phosphatase type 1 family that removes phosphate from serine and/or threonine of phosphoproteins (Ohkura et al., 1989; Sasaki et al., 1990; Barker et al., 1993), whereas PSP fills an important role in the biosynthesis of serine from carbohydrates by catalyzing the last step, hydrolysis of $O$-phosphoserine (MoroFurlani et al., 1980). Therefore, these two enzymes belong to a quite different family that is encoded by each different gene.

In order to confirm our results, the same strategy as reported by Muramatsu et al. (1994) was chosen. As shown in Fig. 2, PCR products (140 bp) were detected in rat, and two rat $\times$ mouse hybrid clones, ts4(4)-C6 and ts1(3)2-A1, which contained RNO7 and several other rat chromosomes without RNO12, whereas no corresponding PCR products were detected in mouse and two other hybrid clones, NA-3-2 and T1A-3, which contained RNO12 and several other rat chromosomes without RNO7 (Table 1). Thus, these results show that the Ppplcc was not located on RNO12 but located on RNO7, confirming the present FISH mapping.

It is of interest to note that chromosomal abnormalities of HSA12, RNO7, and MMU10 are detected in tumor cells (Sasaki, 1982; Wiener et al., 1982; Barbieri 


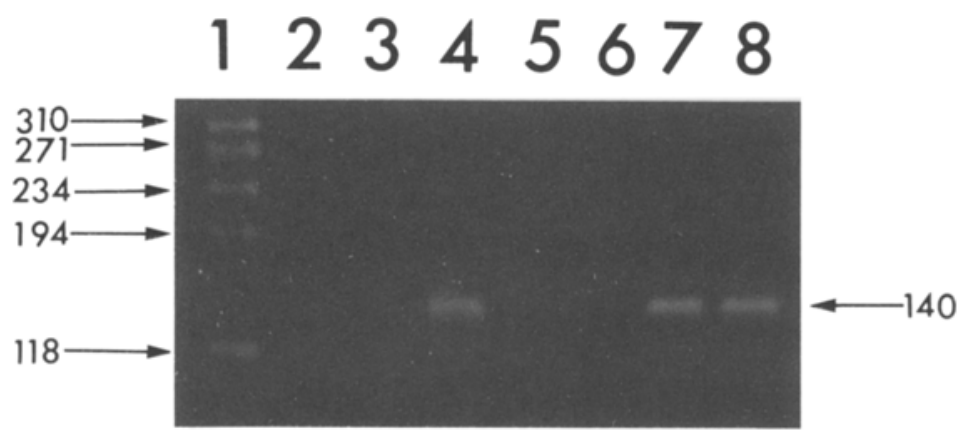

Fig. 2. PCR amplification products were separated by $4 \%$ agarose gel electrophoresis, stained with ethidium bromide, and photographed under UV light. In panel, lanes 1-4 represent, DNA size marker, no DNA, C3H mouse DNA, and WKAH rat DNA. Lanes 5 and 6 represent rat $\times$ mouse hybrid clones NA-3-2 and TIA-3, respectively, which contained RNO12 and several other rat chromosomes without RNO7. Lanes 7 and 8 represent hybrid clones ts4(4)-C6 and ts1(3)2-A1, respectively, which contained RNO7 and several other rat chromosomes without RNO12.

Table 1. Segregation pattern of the protein phosphatase $1 \gamma$ gene (Ppplcc) and rat chromosomes in mouse $\times$ rat somatic cell hybrids.

\begin{tabular}{|c|c|c|c|c|c|c|c|c|c|c|c|c|c|c|c|}
\hline \multirow{2}{*}{$\begin{array}{c}\text { Mouse } \times \text { rat cell } \\
\text { hybrid clone }\end{array}$} & \multicolumn{15}{|c|}{ Rat chromosome } \\
\hline & 1 & 2 & 3 & 4 & 5 & 6 & 7 & 8 & 9 & 10 & 11 & 12 & 13 & 14 & 15 \\
\hline NA-3-2 & - & - & - & - & - & - & - & - & - & - & - & + & - & - & - \\
\hline T1A-3 & - & - & - & - & - & - & - & - & - & - & - & + & - & - & - \\
\hline ts $4(4)-C 6$ & + & + & + & - & + & + & + & - & + & - & + & - & + & - & + \\
\hline $\mathrm{ts} 1(3) 2-\mathrm{A} 1$ & + & - & + & - & - & + & + & + & + & + & + & - & + & + & - \\
\hline \multirow{2}{*}{$\begin{array}{c}\text { Mouse } \times \text { rat cell } \\
\text { hybrid clone }\end{array}$} & \multicolumn{7}{|c|}{ Rat chromosome } & \multirow{2}{*}{\multicolumn{4}{|c|}{$\begin{array}{c}\text { PCR } \\
\text { product }^{\mathrm{b}}\end{array}$}} & & & & \\
\hline & 16 & 17 & 18 & 19 & 20 & $\mathrm{X}$ & $\mathrm{Y}$ & & & & & & & & \\
\hline NA-3-2 & - & - & - & + & - & - & - & & - & & & & & & \\
\hline T1A-3 & - & - & - & - & + & - & - & & - & & & & & & \\
\hline ts $4(4)-C 6$ & + & - & - & + & + & - & - & & + & & & & & & \\
\hline $\operatorname{ts} 1(3) 2-\mathrm{A} 1$ & - & + & - & + & + & - & - & & + & & & & & & \\
\hline
\end{tabular}

${ }^{a}+$, Presence of a rat chromosome in a hybrid clone; - , absence.

${ }^{b}$ Presence $(+)$ or absence $(-)$ of a $140 \mathrm{bp}$ PCR-product of protein phosphatase $1 \gamma$.

et al., 1986; Huret et al., 1988; Kwong et al., 1994) and that the gene encoding PP1 $\gamma$ catalytic subunit located near the fragile sites in human, rat, and mouse chromosomes (Djalali et al., 1987; Robinson and Elder, 1987; Hecht, 1988), rising the possibility that PPPICC may be related to malignancy.

Recently we have mapped the PPl $\alpha$ gene on HSA11q13, RNO1q43, and MMU7E3-F2 (Saadat et al., 1995) and the PP1 $\beta$ gene on HSA2p23, RNO6q21q23, and MMU12D (Saadat et al., 1994). The present data showed that PP1 $\gamma$ gene 
located on HSA12q24, RNO7q22, and MMU10C, indicating that in spite of the high identity of PP1 isoforms, each isoform was encoded by different genes which located on different chromosomes in human, rat, and mouse.

Acknowledgments We would like to thank Dr. Ryuichi Masuda and Dr. Takao Ono in Chromosome Research Unit for their helpful advice and discussion. We wish to express our appreciation to Drs. K. Matsumoto and Y. Muramatsu, Tokushima University, Japan, for their technical suggestions to PCR. This study was supported in part by Grants-in-Aid for Creative Basic Research (Human Genome Program) and Cancer Research from the Ministry of Education, Science and Culture of Japan.

\section{REFERENCES}

Barbieri D, Spanedda R, Castoldio GL (1986): Involvement of chromosomes 12 and 14 in the cutaneous stages of mycosis fungoids: Cytogenetic evidence for a multistep pathogenesis of the disease. Cancer Genet Cytogenet 20: 287-292

Barker HM, Craig SP, Spurr NK, Cohen PTW (1993): Sequence of human protein serine/ threonine phosphatase 1 gamma and localization of the gene (PPPICC) encoding it to chromosome bands 12q24.1-q24.2. Biochim Biophys Acta 1178: 228-233

Cohen P (1989): The structure and regulation of protein phosphatases. A Rev Biochem 58: 453508

Danesino C, Minelli A, Piantanida M, Zuffardi O (1987): Refined mapping of phosphoserine phosphatase (PSP) and b-glucuronidase (GUSB) on chromosome 7 by gene dosage. Ninth International Workshop on Human Gene Mapping. Cytogenet Cell Genet 46: 603

Davisson MT, Lalley PA, Peters J, Doolittle DP, Hillyard AL, Searle AG (1991): Report of the comparative committee for human, mouse and other rodents. Cytogenet Cell Genet 58: 1152 1189

Djalali M, Adolph S, Steinbach P, Winking H, Hameister H (1987): A comparative mapping study of fragile sites in the human and murine genomes. Hum Genet 77: 157-162

Fulchignoni-Lataud MC, Weiss MC, Szpirer C, Levan G (1990): Assignment of the rat genes coding for phenylalanine hydroxylase, tyrosine aminotransferase and pyruvate kinase to chromosomes 6, 19, and 2 respectively. Cytogenet Cell Genet 53: 172-174

Hecht F (1988): Fragile sites update. Cancer Genet Cytogenet 31: 125-128

Huret JL, Brizard A, Briault S, Dreyfus B, Giraud C, Tanzer J (1988): Two additional cases of inv(12) in human malignancies. Cancer Genet Cytogenet 32: 309-311

ISCN (1978): An international system for human cytogenetic nomenclature. Cytogenet Cell Genet 21: $309-404$

Kwong YL, Pang J, Ching LM, Liu HW, Liang RHS, Chan LC (1994): Trisomy 12 in chronic lymphocytic leukemia. An interphase cytogenetic study by fluorescence in situ hybridization. Cancer Genet Cytogenet 72: 83-85

Lalley PA, Diaz JA (1984): Comparative gene mapping in the mouse involving genes assigned to human chromosomes 7 and 20. Seventh International Workshop on Human Gene Mapping. Cytogenet Cell Genet 37: 514-515

Levan G, Szpirer J, Szpirer C, Klinga K, Hanson C, Islam MQ (1991): The gene map of the Norway rat (Rattus norvegicus) and comparative mapping with mouse and man. Genomics 10: $699-718$

Li SZ, Oikawa T, Yoshida MC, Naito H, Kuzumaki N (1989): Regional mapping of the FOS oncogene to rat chromosome 6q21-q23. Cytogenet Cell Genet 52: 42-44

Moro-Furlani AM, Turner VS, Hopkinson DA (1980): Genetic and biochemical studies on human phosphoserine phosphatase. Ann Genet 43: 323-333 
Muramatsu Y, Yamada T, Yamada J, Serikawa T, Matsumoto K (1994): Chromosomal assignment of the gene for rat protein phosphatase $1 \gamma 1$ (Ppplcc). Cytogenet Cell Genet 67: 58-60

Ohkura H, Kinoshita N, Miyatani S, Toda T, Yanagida M (1989): The fission yeast dis2+ gene required for chromosome disjoining encodes one of two putative type 1 protein phosphatases. Cell 57: 997-1007

Robinson TJ, Elder FFB (1987): Multiple common fragile sites are expressed in the genome of the laboratory rat. Chromosoma (Berl) 96: 45-49

Saadat M, Kakinoki K, Mizuno Y, Kikuchi K, Yoshida MC (1994): Chromosomal localization of human, rat, and mouse protein phosphatase type $1 \beta$ catalytic subunit genes $(P P P I C B)$ by fluorescence in situ hybridization. Jpn J Genet 69: 697-700

Saadat M, Mizuno Y, Kikuchi K, Yoshida MC (1995): Comparative mapping of the gene encoding the catalytic subunit of protein phosphatase type $1 \alpha(P P P I C A)$ to human, rat, and mouse chromosomes. Cytogenet Cell Genet 70: 55-57

Sasaki K, Shima H, Kitagawa Y, Irino S, Sugimura T, Nagao M (1990): Identification of members of the protein phosphatase 1 gene family in the rat and enhanced expression of protein phosphatase $1 \alpha$ gene in rat hepatocellular carcinomas. Jpn J Cancer Res 81: 12721280

Sasaki M (1982): Current status of cytogenetic studies in animal tumors with special reference to nonrandom chromosome changes. Cancer Genet Cytogenet 5: 153-172

Wiener F, Babonits M, Spira J, Klein G, Bazin H (1982): Non-random chromosomal changes involving chromosomes 6 and 7 in spontaneous rat immunocytomas. Int J Cancer 29: 431437

Vol. 41, No. 1, 1996 